PSYCHOMETRIKA-VOL. 43 , NO. 4 .

DECEMBER, 1978

ERRATA

\title{
ERRATA TO \\ OPTIMAL SCALING OF PAIRED COMPARISON AND RANK ORDER DATA: AN ALTERNATIVE TO GUTTMAN'S FORMULATION
}

\section{SHIZUHIKo NishisATO}

THE ONTARIO INSTITUTE FOR STUDIES IN EDUCATION follows:

Two formulas in Nishisato [1978] were erroneous. The correct versions of them are as
Formula (9), p. 265
Errors are
Should be
$S S_{t}=2 N \mathrm{x}^{\prime} \mathrm{x}$
$S S_{t}=N(n-1) x^{\prime} \mathbf{x}$
Formula $(10)$, p. $266 \quad S S_{\diamond}=\left[\frac{2}{n(n-1)^{2}}\right] \mathrm{x}^{\prime} E^{\prime} E \mathrm{x}$
$S S_{o}=\left[\frac{1}{n(n-1)}\right] x^{\prime} E^{\prime} E x$

The other formulas and the discussion are correct.

\section{REFERENCE}

Nishisato, Shizuhiko. Optimal scaling of paired comparison and rank order data: An alternative to Guttman's formulation. Psychometrika, 1978, 43, 263-271. 